\title{
Ribosomal DNA-connecting ribosome biogenesis and chromosome biology
}

\author{
Lev Porokhovnik • Jennifer L. Gerton
}

Received: 18 December 2018 / Accepted: 19 December 2018 /Published online: 21 January 2019

(C) Springer Nature B.V. 2018

\begin{abstract}
Ribosomal DNA, the topic of this special issue, has long fascinated biologists. The RNA products of the ribosomal DNA are the ribosomal RNAs that are part of the ribosome. In this special issue, we focus on the sequence, molecular organization, repair, stability, copy number, and peculiar genetics of this region of the genome. The locus can impact not only the translational capability of cells, but also genome organization, stability and integrity, providing a link between translation and chromosome biology.
\end{abstract}

\section{Abbreviation \\ UVA Ultraviolet A \\ piRNA piwi-interacting RNA}

Ribosomal RNA is the major non-protein catalytic molecule in the cell. A hypothetical early stage in the

Responsible Editor: Beth A. Sullivan

L. Porokhovnik $(\bowtie)$

Research Centre for Medical Genetics, 1 Moskvorechie str, Moscow 115478, Russia

e-mail: med-gen@mail.ru

J. L. Gerton

Stowers Institute for Medical Research, 1000 E. 50th St, Kansas City, MO 64110, USA

e-mail: jeg@stowers.org

\section{J. L. Gerton}

University of Kansas Medical Center, 3901 Rainbow Blvd., Kansas City, KS 66160, USA evolutionary history of life on Earth termed "RNA world" has been postulated, in which self-replicating RNA molecules proliferated before the evolution of DNA and proteins. According to this hypothesis, RNA stored genetic information and simultaneously catalyzed chemical reactions. Different RNAs diverged in primitive cells to become specialized as either heredity carriers or catalytic molecules. Only later in evolutionary time did DNA take over as the genetic material and proteins become the major catalyst and structural component of the cell. A molecular fossil of the ribozyme activity of archetypal ribonucleoproteins is the ribosome, a protein-synthesizing protein-RNA machine that can be found in almost every cell. Ribosomes, first observed with an electron microscope as dense particles or granules in 1955 by George Palade (Palade 1955), a future Nobel laureate, are megaDalton-sized cytoplasmic ribonucleoprotein complexes. Their function is translation of the genetic code written in DNA to the amino acid sequence of proteins, the diversity and multiplicity of which determines the development, morphology, and physiology of every living organism.

Eukaryotic ribosomes consist of large and small subunits with sedimentation coefficients of $60 \mathrm{~S}$ and $40 \mathrm{~S}$, respectively. Ribosomes are composed of the major ribosomal RNAs $(28 \mathrm{~S}, 18 \mathrm{~S}, 5.8 \mathrm{~S}$, and $5 \mathrm{~S}$ ) and a complex of approximately 80 ribosomal proteins, with $\sim 50$ proteins in the large subunit, and $\sim 30$ proteins in the small subunit (de la Cruz et al. 2015). Genes coding for ribosomal RNA are found together in repeat clusters in eukaryotic genomes. Each repeated unit consists of a transcribed region with a gene encoding $18 \mathrm{~S}, 28 \mathrm{~S}$, and 
5.8S rRNAs, and a non-transcribed spacer region. In many genomes, including the human genome, the gene repeat cluster encoding the 5S rRNA is located in a separate locus or loci.

Ribosomal RNA accounts for up to $60-80 \%$ of the total cellular RNA. While these RNAs have been widely assumed to be identical, recent work suggests that there may be more heterogeneity at the DNA (Kim et al. 2018; Xu et al. 2017) and RNA level (Kim et al. 2018; Parks et al. 2018) in the human genome than previously suspected (reviewed by Matthew Parks and colleagues). This has interesting implications for ribosomes, since ribosomes with different versions of the ribosomal RNAs have the potential to have different translational properties.

The eukaryotic cell contains 1.5 to 3 million ribosomes. During one cell cycle, up to 10 million ribosomes are synthesized de novo. For this reason, the cell needs many copies of ribosomal genes in order to meet the demand for ribosomal RNA in making ribosomes. The ribosomal repeats are abundant in every eukaryotic genome and in most prokaryotic genomes. Ribosomal repeats range from 1 to 13 in bacteria and up to several thousand in some plants, amphibians, and fishes. In most large warm-blooded animals and humans, the number of ribosomal repeats varies between 150 and 220 copies per haploid genome (Long and Dawid 1980).

The full nucleotide sequence of the human $45 \mathrm{~S}$ ribosomal repeat (GeneBank: U13369) was determined prior to sequencing most other human genes (Wellauer and Dawid 1979). However, due to the size and number of repeats, the ribosomal DNA regions of the human acrocentric chromosomes remain unassembled at the end of 2018, despite the completion of the human genome in 2003. New long read technologies may help to resolve this "hole" in the human reference genome. Furthermore, specialized computational methods are being developed to analyze this locus in sequencing data (Agrawal and Ganley 2016; Gibbons et al. 2014).

The question of repeat copy number is an interesting one that can impinge on both genome function and translational capacity. Changes to total copy number, as well as to the number of active copies, may provide a mechanism to vary the amount of ribosomal RNA produced, and may further impact organismal health and disease. These topics are addressed for the human genome in a review by Lev Porokhovnik and Nataliya Lyapunova. The role of repeat copy number in heterochromatin and transgenerational inheritance, using
Drosophila as a model system, is reviewed by Farah Bughio and Keith Maggert.

Ribosomal RNAs are transcribed by RNA polymerase I with accompanying transcription factors and chromatin marks. While the RNA polymerase machinery is unique to this locus, many of the chromatin marks and genome organizing proteins function in other areas of the genome too. The chromatin landscape is reviewed by Thomas Moss and colleagues, while the effect of UVA irradiation on interactions between chromatin proteins is explored in an original article by Lenka Stixová and colleagues.

The transcription of this region occurs at such an extraordinarily high level, especially during rapid proliferation or in stress conditions, it can interfere with repair and make it vulnerable to single-strand and double-strand breaks. Furthermore, the head to tail repeat structure may be a challenge for the replication and repair systems in terms of copy number maintenance. The rDNA has a unique potential to act as a "canary in the coalmine," being particularly sensitive to genomic stresses, and possessing the ability to adapt its copy number. The repair, stability, and adaptability of the ribosomal DNA is addressed by two reviews, one by Daniel Warmerdam and Rob Wolthuis and one by Devika Salim and Jennifer Gerton. Olga Zatsepina has contributed an original article that explores the stability of these regions in a mouse cell line using cytogenetics.

The ribosomal DNA clusters are organized into nucleoli, the sites in the nucleus where RNA polymerase I transcribes the ribosomal RNAs that are then processed, modified, and partly assembled with ribosomal proteins. However, the nucleolus is also multifunction, and participates in the formation of signal recognition particles, and in the response to stress. The nucleolus was one of the first organelles recognized under the microscope due to its prominence and density, first formally described between 1835 and 1839 independently by Wagner and Valentin. Barbara McClintock was the first person to name a part of the chromosome as the nucleolar organizing region (McClintock 1934), which was later realized to correspond with the ribosomal DNA. This organization certainly impacts ribosomal DNA repeats, but also many other associated regions of the genome (Nemeth and Langst 2011). A review article from Tamara Potapova and Jennifer Gerton addresses the proteins and models for organization of ribosomal DNA into nucleoli. Helena Fulka and Alena Langerova address how nucleoli might serve as a central structural 
platform for chromatin remodeling in embryos. Several RNAs and proteins may shuttle in and out of the nucleolus, often for unknown reasons. An original article contributed by Elena Mikhaleva and colleagues characterizes the piRNA binding protein Piwi as a visitor to the nucleolus in cultured ovarian somatic cells from Drosophila, setting up an interesting model for the study of Piwi and its role in silencing.

The next few years should provide significant advances in our understanding of the sequence and genomic properties of the ribosomal DNA, given the rapid advances in sequencing technology. The advent of super-resolution microscopy will further aid in the study of ribosomal DNA, nucleoli, and how nucleoli attain their status as a non-membrane bound organelle. Furthermore, advances in proteomics make it possible to quantitatively analyze the composition of the nucleolar proteome in low abundance cell types. These new technologies will help inform genetic, cell biological, and biochemical studies that will no doubt be revealing about this unusual and perpetually fascinating locus. The locus can impact not only the translational capability of cells, but also genome organization, stability and integrity, providing a link between translation and chromosome biology (Kobayashi 2011).

Publisher's Note Springer Nature remains neutral with regard to jurisdictional claims in published maps and institutional affiliations.

\section{References}

Agrawal S, Ganley AR (2016) Complete sequence construction of the highly repetitive ribosomal RNA gene repeats in eukaryotes using whole genome sequence data. Methods Mol Biol 1455:161-181 de la Cruz J, Karbstein K, Woolford JL Jr (2015) Functions of ribosomal proteins in assembly of eukaryotic ribosomes in vivo. Annu Rev Biochem 84:93-129

Gibbons JG, Branco AT, Yu S, Lemos B (2014) Ribosomal DNA copy number is coupled with gene expression variation and mitochondrial abundance in humans. Nat Commun 5:4850

Kim JH, Dilthey AT, Nagaraja R, Lee HS, Koren S, Dudekula D, Wood Iii WH, Piao Y, Ogurtsov AY, Utani K, Noskov VN, Shabalina SA, Schlessinger D, Phillippy AM, Larionov V (2018) Variation in human chromosome 21 ribosomal RNA genes characterized by TAR cloning and long-read sequencing. Nucleic Acids Res 46:6712-6725

Kobayashi T (2011) Regulation of ribosomal RNA gene copy number and its role in modulating genome integrity and evolutionary adaptability in yeast. Cell Mol Life Sci : CMLS 68:1395-1403

Long EO, Dawid IB (1980) Repeated genes in eukaryotes. Annu Rev Biochem 49:727-764

McClintock B (1934) The relation of a particular chromosomal element to the development of the nucleoli in Zea mays. Z Zellforsch Mikrosk Anat 21:294-326

Nemeth A, Langst G (2011) Genome organization in and around the nucleolus. Trends in genetics : TIG 27:149-156

Palade GE (1955) A small particulate component of the cytoplasm. J Biophys Biochem Cytol 1:59-68

Parks MM, Kurylo CM, Dass RA, Bojmar L, Lyden D, Vincent CT, Blanchard SC (2018) Variant ribosomal RNA alleles are conserved and exhibit tissue-specific expression. Sci Adv 4: eaao0665

Wellauer PK, Dawid IB (1979) Isolation and sequence organization of human ribosomal DNA. J Mol Biol 128:289-303

Xu B, Li H, Perry JM, Singh VP, Unruh J, Yu Z, Zakari M, McDowell W, Li L, Gerton JL (2017) Ribosomal DNA copy number loss and sequence variation in cancer. PLoS Genet 13:e1006771 